\title{
Willingness to Pay for Environmental Quality: The Effects of Pro-Environmental Behavior, Perceived Behavior Control, Environmental Activism, and Educational Level
}

\author{
Paula Vicente' (ID, Catarina Marques', and Elizabeth Reis'
}

\begin{abstract}
Environmental quality is one of the major concerns in contemporary societies. The main goal of this research is to investigate citizens' willingness to pay for environmental quality and whether this propensity differs in line with education level. Structural equation modeling is used to explore the associations between several constructs; specifically, a multigroup analysis is conducted to assess the invariance of two educational level segments.

Results suggest that willingness to pay more for environmental quality is positively associated with perceived behavior control and environmental activism. Pro-environmental behavior does not impact willingness to pay for environmental quality but is positively related to perceived behavior control and environmental activism. The relationships between constructs hold true for both groups of education. Implications for public policy and marketing actions are addressed.
\end{abstract}

\section{Keywords}

environmental activism, perceived behavior control, pro-environmental behavior, willingness to pay, educational level, Portugal

\section{Introduction}

Concern for environmental quality has entered the mainstream culture in advanced industrialized countries. The increased environmental awareness and willingness to actively contribute to social and environmental well-being drive people into personal sacrifices and lifestyle changes to help overcome the world's environmental problems (Cone Communications 2015; Franzen \& Meyer, 2009; Ivanova \& Tranter, 2004; Thornton, 2009). An isolated pro-environmental action by a single individual or entity has little effect, but the sum of actions by an entire population can bring about significant environmental gains (Lavik, 2002). As such, environmental protection is a collective challenge that involves governments, organizations, and individuals (Hohnen, 2007; United Nations 2008, 21st Session of the Conference of the Parties, 2015). Governments have various tools at their disposal to reduce environmental damage; these range from regulations, information programs, innovation policies, environmental subsidies, and environmental taxes. Organizations can make their contribution to environmental protection by following federal, state, and local environmental laws, by choosing green energy systems, reducing excessive packaging, using recycled products, and offering business promotions that raise awareness of environmental issues (e.g., offering customers a free or discounted item when they bring in a recyclable bag or box) (Thompson, 2017).

At the individual level, the different types of environmental actions adopted depend on how public and radical a person's support for sustainability is (Castro et al., 2017): (a) activist behaviors, (b) private sphere behaviors, and (c) moderate activist behaviors in the public sphere. Activist behaviors involve an active fight in defense of the environment and seek to change the way society deals with the environmental issue. They include participating in public awareness events, debates on environmental protection, and direct involvement with organizations that aim to defend everything related to the environment (e.g., Greenpeace) (Stern, 2000). Private

'Iscte-Instituto Universitário de Lisboa, Portugal

Corresponding Author:

Paula Vicente, Business Research Unit (BRU-Iscte), Iscte-Instituto Universitário de Lisboa, ISCTE-IUL, Av. Forças Armadas, Lisboa I649-026, Portugal.

Email: paula.vicente@iscte-iul.pt 
sphere behaviors are those that individuals (or households) adopt out of solidarity and on a voluntary and daily basis in favor of environmental sustainability. These behaviors may include buying green products, waste recycling, water and energy saving, or reducing the use of the private car, that is, behaviors which are closely linked to people's daily lives (Kashima et al., 2014). Moderate activist behaviors in the public sphere are a form of moderate activism in which activities are less risky than engaged activism but demonstrate public support for environmental causes (Stern, 2000). They include "writing letters to political officials, signing petitions, making financial contributions to environmental movements, sharing information through social media or informal conversations" (Castro et al., 2017, p. 5).

Paying higher taxes or higher prices for environmentally friendly products is another example of moderate activist behavior (Orecchia \& Zoppoli, 2007; Organisation for Economic Co-Operation and Development [OECD], 2003). The main objective of environmental charges or taxes is to internalize the external costs caused by producers' production and/or consumers' activities. Governments in the European Union (EU) and the OECD countries use taxing mechanisms, such as charges on emissions, products, wastewater, solid waste, noise, and tax differentiation, among others. Similarly, eco-friendly products (both food and non-food) are sold at higher prices than regular products to support the more costly production process, which is usually work force intensive, time-consuming, with low production rates and entails high certification costs. However, as the benefits are expected to balance the costs in terms of health and sustainable living, many people choose to buy these products regardless of the expense. Paying higher prices or higher taxes have been used as an indicator of the degree of public support for environmental policies since accepting a policy must be linked to the willingness to finance it (Gelissen, 2007; Jin \& Shriar, 2013; Stern et al., 1999). As such, it is important that governments and policy makers know how willing people are to pay before implementing strategies aimed at proposing alternative culture and lifestyle models and at encouraging individuals to engage in pro-environmental actions (Punzo et al., 2019).

Intentions represent an individual's conscious motivation or willingness to try to engage in a particular behavior (Ajzen, 1991). Within the present research, citizens' willingness to pay for environmental quality could be perceived as an eco-friendly intention that reflects the individual's consideration of environment protection and readiness to perform eco-friendly behaviors. Drawing from the ecofriendly behavior literature and based on the different conceptual frameworks, this article proposes a model to investigate the influencing factors of willingness to contribute monetarily toward environmental quality and estimates this using structural equation modeling (SEM). In the context of environmental research, several theoretical frameworks are used to investigate pro-environmental intentions and/or pro-environmental behaviors (PEBs), namely the theory of planned behavior (TPB), and the norm activation model (NAM).

The TPB (Ajzen, 1985, 1991; Fishbein \& Ajzen, 2010) is one of the most powerful predictive persuasion theories and has been used to study a variety of environmental behaviors (Armitage \& Conner, 2001). According to this theory, intention is the only direct determinant of behavior; however, the intention to perform the behavior is a function of attitudes toward the behavior, subjective norms, and perceived behavioral control. The NAM (Schwartz, 1977) explains people's altruistic and pro-social behaviors (De Groot \& Steg, 2009). In the context of environmental research, NAM has been applied to study several pro-environmental intention/behaviors, including environmental activism (EA) (Liobikien \& Poškus, 2019).

To the best of our knowledge, intention to pay for environmental quality has not been studied using the SEM approach but analogous concepts such as willingness to pay for environmentally friendly products or the intention to purchase green products were investigated using conceptual models of interrelated independent variables. For example, Nezakati et al. (2014) selected the TPB to build a model aimed to investigate the intention to purchase green products; Al Mamun et al. (2018) propose a model derived from the TPB model to explain both willingness to pay for environmentally friendly products and payment behavior for environmentally friendly products. Parallel to this, we find several investigations into pro-environmental intentions, exploring the effect of specific factors based on context-specific models: Han et al. (2011) investigated whether personal attitudes (i.e., regarding severity of environmental problems, inconvenience of being environmentally friendly, importance of being environmentally friendly, and level of responsibility of business corporations) affect the intentions to pay more for a green hotel; Trivedi et al. (2015) proposed a model in which willingness to pay for environmentally friendly products is explained by PEB and environmental locus of control; Biswas (2016) investigates the association and interaction of consumers' perceptual or behavioral factors, external contextual factors, and responsiveness to corporate environmental performance on willingness to pay price premium for green products; Dursun et al. (2016) examines the predictive power of six self-determined motivational types and value orientations to two types of pro-environmental intentions-preference for a high environmental performance car and intention to donate to an environmental organization; Sang et al. (2020) developed a research model to explain the influencing factors of consumers' willingness to purchase green housing.

Various studies on the determinants of individuals' willingness to pay for eco-friendly products or environment protection found strong correlations with sociodemographic factors (Davis et al., 2011; Gelissen, 2007; Haller \& Hadler, 2008; Ivanova \& Tranter, 2008; Kyselá, 2015; Marbuah, 
2016; Witzke \& Urfei, 2001). This suggests that willingness to pay for the environment is not uniform but varies across segments of the population. Specifically, education was found to be one of the most important indicators of willingness to pay higher taxes for environmental protection in several European countries - the higher the level of education, the more willing people are to pay higher taxes (Ivanova \& Tranter, 2008).

The current study proposes a model to explore the association between environmental-related factors - namely PEBs, perceived behavior control (PBC), and EA-and the intention to pay for environmental quality. The effect of education in the model's relationships is also analyzed. More specifically, education is included as a moderator in the model, and a multigroup SEM analysis is conducted to assess the invariance of two educational segments - people with university education and people without university education. Differences in the relationships among model constructs between the two groups mean that distinct approaches are needed so that public policies and marketing decisions can target each audience effectively. The model is tested using data from a survey on consumption and natural environment of Portuguese households. In Portugal, citizens' involvement in pro-environmental activities has been limited, and little research has been done to understand what could drive citizens to be more cooperative with eco-friendly initiatives.

The remainder of this article is organized as follows. The next section provides the theoretical foundation and details the research hypotheses. Third section introduces the study context, the data and the methodology used to test the basic hypotheses. Fourth section discusses the main empirical results. Fifth section provides discussions and policy evaluations, concluding with some suggestions for future studies.

\section{Theoretical Foundation and Research Hypotheses}

\section{Theoretical Foundation}

The TPB claims that an individual's behaviors are directly affected by behavioral intentions, which are, in turn, influenced by the attitude toward the behavior (what do I think?), subjective norms (what other people think?), and perceived behavioral control (can I do it?) (Ajzen, 1991, 2002, 2020) The stronger these dimensions are, the more likely someone is to form a behavioral intention to take the action and consequently, act. Attitude toward the behavior (ATB) refers to the individual's evaluation of a certain behavior and is a function of readily accessible beliefs. Subjective norms (SN) is a social dimension that refers to the pressure the society puts on the individual to perform or not perform a certain behavior, that is, the expectation or subjective probability that a given individual or group approves or disapproves of performing the behavior under consideration. Perceived behavioral control (PBC) is based on accessible control beliefs and refers to the self-perceived ease or difficulty of performing the behavior, a subjective probability that a given facilitating or inhibiting factor will be present, resulting from both past experiences and expected future obstacles. TPB has been used several times in environmental research to measure peoples' acceptance and adoption of pro-environmental intentions and/or PEBs. For example, the TPB has successfully predicted the determinants of recycling behaviors (Mannetti et al., 2004), the willingness of young Indian consumers to visit green hotels (Verma \& Chandra, 2018), and the willingness of consumers to purchase genetically modified food in their grocery store shopping (O'Fallon et al., 2007).

The NAM claims that pro-environmental actions occur in response to personal norms, defined as the person's feeling of a moral obligation to perform or renounce from specific actions (Schwartz \& Howard, 1981). This means that an individual's PEB is determined by the degree of his or her personal responsibility for such behavior, which is reflected in his or her personal norm. NAM assumes that the process of norm activation is determined by two factors: awareness of consequences and ascription of responsibility. In other words, if an individual is aware of problems caused by certain behaviors, this awareness is followed by the consideration of his or her own contribution to those problems and whether he or she can help resolve them. In addition, NAM has explained pro-environmental intentions and behaviors by integrating the TPB model and expanding the variables in the model. The integration of TPB and NAM in a comprehensive framework was used to explain consumers' willingness to choose organic menus in restaurants (Shin et al., 2018), to purchase green housing (Han, 2014; Sang et al., 2020), and to identify the determinants of environmental complaints (Zhang et al., 2017). This integrative model includes rational and moral considerations and provides a deep understanding of the variables that affect consumers' willingness to adopt a specific behavior.

\section{Research Hypotheses}

Pro-environmental behavior. Pro-environmental behavior (PEB) is generally judged in the context of the society as a protective type of environmental behavior - that is, behavior which has a significant and positive impact on the environmentor a tribute to the healthy environment (Krajhanzl, 2010). Some studies recognize the positive correlation between PEB and willingness to pay for the environment; for instance, Oreg and Katz-Gerro (2006) have established a positive relationship between willingness to pay for environmental protection and PEB in a 27-country sample; van Birgelen et al. (2011) found a positive relationship between PEB and individuals' willingness to pay higher airfares to protect the environment.

The TPB posits that behaviors are immediately determined by behavioral intentions (Ajzen, 1991; Fishbein \& 
Ajzen, 2010). In the specific context of environmental protection research, this means that adopting a specific PEB is proceeded by the intention to implement this PEB. Each person can simultaneously adopt several and diverse PEBs, such as recycling, using public transport instead of the private car, or giving money to an environment protection organization (e.g., Rajapaksa et al., 2018; Wang et al., 2020) and what the person already does in favor of the environment can have either a positive or negative effect on his or her intention to also adopt other PEBs. Dono et al. (2010) found that consumer behavior affects willingness to sacrifice for environmental protection; Trivedi et al. (2015) found that consumers who already have eco-friendly behaviors (e.g., using the bike, saving energy) are more willing to pay for environmentally friendly products, and Marbuah (2016) found that citizens who already cut back on driving or avoid buying non-green products are more willing to pay higher taxes and to accept cuts in their standard of living to protect the environment. In such circumstances, PEBs are precursors of the intention/willingness to act (even more) in an eco-friendly way. Drawing from this, our model explores the effect of already adopted eco-friendly behavior on the intention to go further in favor of the environment and accept making a monetary contribution to environmental quality. We therefore hypothesize the following:

Hypothesis 1 (H1): Pro-environmental behavior (PEB) is positively related to willingness to pay (WTP) for environmental quality.

Perceived behavior control. Perceived behavior control (PBC) is a construct of the TPB model and is focused on the ability to perform a particular behavior. It provides useful information about the actual control an individual can exercise in a specific situation: A high level of $\mathrm{PBC}$ should increase effort and perseverance to perform the behavior. In the TPB, PBC refers to "people's expectations regarding the degree to which they are capable of performing a given behavior, the extent to which they have the requisite resources and believe they can overcome whatever obstacles they may encounter" (Ajzen, 2002, p. 677). When people believe that they have the required resources and opportunities (e.g., skills, time, money, cooperation by others) and that the obstacles they are likely to encounter are few and manageable, they should have confidence in their ability to perform the behavior and thus exhibit a high degree of PBC (Ajzen, 2002). PBC is also likely to affect intentions - a high level of perceived control should strengthen a person's intention to perform the behavior (Ajzen, 2002). PBC can be directly measured by questions about the ability to perform a behavior, or indirectly by the beliefs about the capacity to deal with specific facilitating or inhibiting conditions.

Several empirical studies have isolated PBC as a crucial antecedent of pro-ecological behavior and intentions. Afroz et al. (2015) and Wang et al. (2016) suggest that the intention to change to green vehicles is significantly influenced by consumers' perceived behavioral control; Maichum et al. (2016), Chen (2017), Tan et al. (2017), and Al Mamun et al. (2018) indicate that PBC has a direct influence on the willingness to buy environmentally friendly products; Sang et al. (2020) found that PBC has a positive influence on consumers' willingness to purchase green housing in China. Therefore, individuals' high degree of self-control can generate a strong desire to perform a specific behavior (Gao et al., 2017). Furthermore, Wu and Chen (2014) provided empirical evidence that high PBC does have a significantly positive impact upon both consumers' behavioral intention and actual behavior. Therefore, in our model we hypothesize the following:

Hypothesis 2 (H2): Perceived behavior control (PBC) is positively related to pro-environmental behavior.

Hypothesis 3 (H3): Perceived behavior control (PBC) is positively related to willingness to pay for environmental quality.

Environmental activism. Environmental activism (EA) has been conceptualized as a function of specific behaviors aimed at protecting the natural environment, especially from the harmful effects of human activity. Examples of such behavior include having environmental group membership, intentionally performing difficult environmental behaviors, engaging in political action, having an active involvement in environmental organizations, having the potential to influence policy or management decisions, and taking part in environmental protests (Dono et al., 2010; Jones et al., 2010; Marbuah, 2016). Stern (2000) suggests that EA is a subtype of PEB and Dono et al. (2010) argue that EA and PEBs are positively related. Therefore, we hypothesize the following:

Hypothesis 4 (H4): Environmental activism (EA) is positively related to pro-environmental behavior.

Jones et al. (2010) state that participation in civic activities influences an individual's tendency to engage in collective activities that preserve the environment and hence their willingness to pay for environmental protection. Marbuah (2016) found that membership of an environmental organization and donating money to an environmental organization increase the probability of agreeing to higher environment taxes and to cuts in the standard of living. As such, we hypothesize:

Hypothesis 5 (H5): Environmental activism (EA) is positively related to willingness to pay for environmental quality.

Moderating effect of educational level. Research on willingness to pay for eco-friendly products or environment protection found strong correlations between these constructs and 


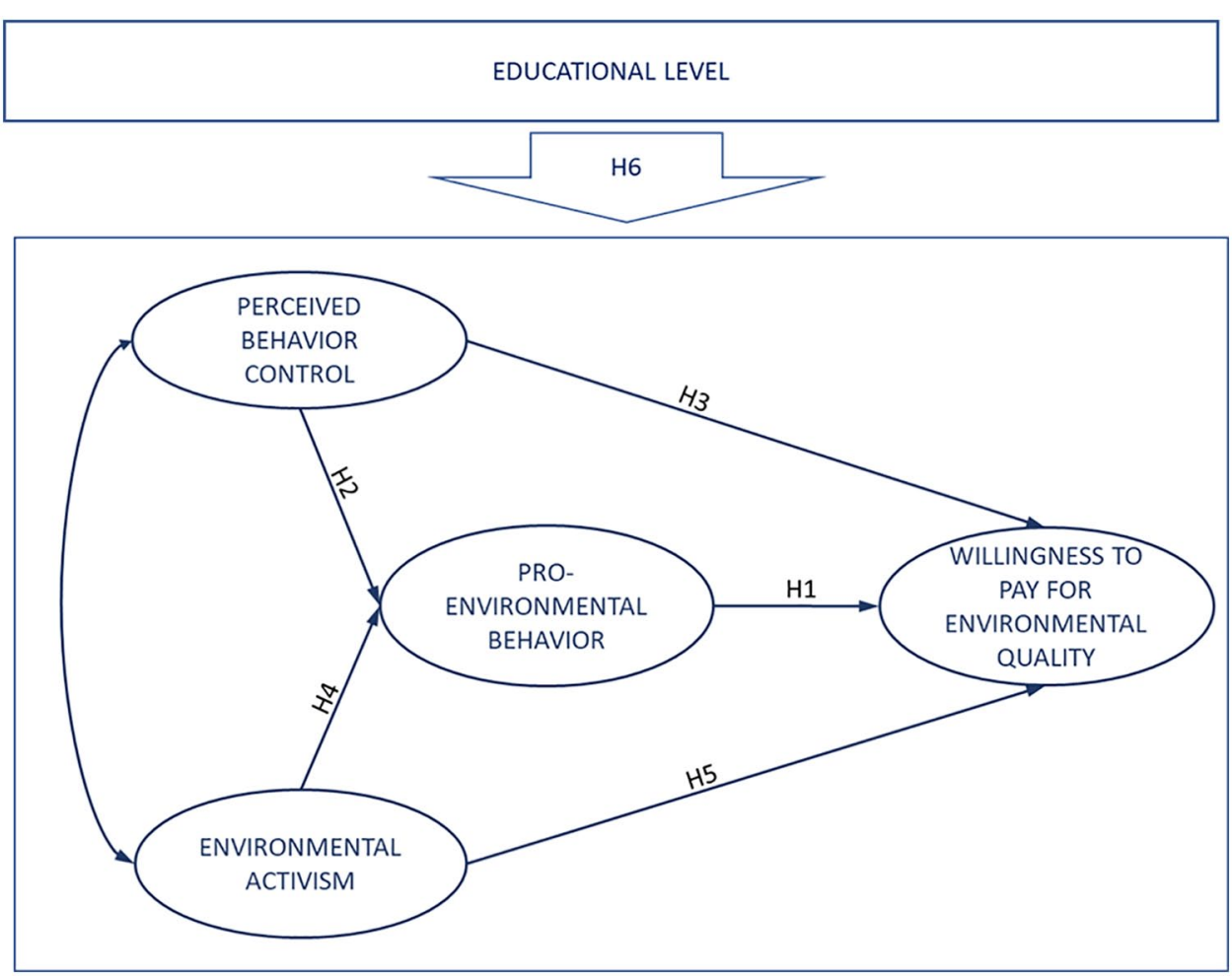

Figure I. Conceptual model for willingness to pay for environment quality.

sociodemographic factors (Davis et al., 2011; Gelissen, 2007; Haller \& Hadler, 2008; Ivanova \& Tranter, 2008; Kyselá, 2015; Marbuah, 2016; Witzke \& Urfei, 2001). Specifically, Ivanova and Tranter (2008) found that education is an important determinant of willingness to pay higher taxes for environmental protection in several European countries: The higher the level of education, the more willing people are to pay higher taxes. Therefore, we hypothesize the moderating effect of education as follows:

Hypothesis 6 (H6): The relationships among the model constructs are stronger for people with university education than for those without university education.

Proposed research model. Based on the discussion above, Figure 1 shows the theoretical research framework and hypotheses relationships of this study. The model combines TPB and NAM to construct a model that considers the effects of PBC, EA, PEB, and educational level to predict citizens' willingness to pay for environment quality, as shown in Figure 1. The TPB model supports the relationships expressed in $\mathrm{H} 1, \mathrm{H} 2$ and $\mathrm{H} 3$. The NAM supports, although implicitly, the relationships expressed in $\mathrm{H} 4$ and $\mathrm{H} 5$, that is, the underlying personal norms are implicitly responsible for one's response to EA, PEB, and WTP for environmental quality.

\section{Research Context, Data Collection, and Methods}

\section{Study Context}

In Portugal, environmental protection is a relatively recent issue in both the political agenda and citizens' discourse. It was only in 1976, after the fall of the dictatorial regime that had ruled the country for nearly 50 years, that environmental rights were enshrined in the Portuguese Constitution. The first Non-Governmental Environmental Organization (Quercus) was formed in 1985, and the Basic Law on environmental matters was passed in 1987. Portugal's entry in the European Economic Community (EEC) in 1986 was a decisive milestone for the national environmental policy. It was an external engine for nearly all legislative and administrative production in the following years and made environment policy more visible and agile. Moreover, the EEC funding lines in conjunction with political and legal aspects associated with the principles of economic and social cohesion were of the utmost importance to the formation of a national environmental policy (Soromenho-Marques, 2005).

As a member of the EU, Portugal's legal, institutional, and administrative framework for environmental matters soon converged with that of other EU member states. Portugal also signed the Kyoto Protocol. However, implementation in both domestic and global settings has been the country's main 
challenge. The European Environment Agency (EEA) considers that the Portuguese Government is not doing enough either to foster the advancement or to initiate additional appropriate reforms, although it recognizes the significant advances made in environmental protection, notably in the protection of marine environments (Sustainable Governance Indicators, 2016).

At the societal level, Portugal lacks a culture of civic participation and intervention. In 2009, about three-fourths of the population did not protest or participate/cooperate with civic life associations (the OECD average was approximately $45 \%$ ) (Rafail \& Freitas, 2017). This makes it more difficult to mobilize citizens to become more responsible and actively foster a truly sustainable lifestyle (Tavares, 2013). Not only is there little engagement in environmental protection activities by Portuguese citizens but research on this topic is also lacking. The scant research has focused mainly on understanding households' participation in recycling (Valle et al., 2004, Vicente \& Reis, 2007, 2008) and the consumption of green products (Paço \& Raposo, 2009, 2010, Schoor, 2013; Silva, 2015), but the outcomes are far from encouraging. For example, the household recycling rate in 2017 was just $28.4 \%$ (Pordata 2019), well below the goal of $50 \%$ set for 2020 despite considerable efforts to modernize sorting equipment and to strengthen selective collection networks (Agência Portuguesa do Ambiente [APA] 2014). There are however important differences across subgroups of the population: non-recyclers are mostly lower social class (C2/D) (59\%) and aged 37 to 57 years (42\%) (Marktest, 2019).

\section{Sample}

Data come from a survey on consumption and natural environment collected by means of household in-person interviews covering the south of Portugal (territory below the Tagus River). Strata was defined by region according to NUTS II (NUTS is a hierarchical system of division of the territory into regions; at national level, the NUTS II division encompasses seven regions). In each stratum, interviewers were assigned in teams of two or three to randomly selected sampling areas; they were given a map and detailed instructions on how to move within the sampling areas to assure good geographical coverage. The sampling procedure to select the buildings was very like a random-route procedure. No more than two households could be interviewed in the same building; an individual aged 18 or older was interviewed in each selected household that agreed to cooperate after confirming interrelated quotas of sex and age. Respondent's education level was controlled by means of marginal quotas.

A sample of 595 respondents was obtained: $42.9 \%$ males, $26.7 \%$ aged 25 to 34 years, $56.8 \%$ highly educated (graduates or postgraduates), and $51.1 \%$ living in families with no children. Approximately $50 \%$ are employed by a third party; most respondents have a monthly household income of $€ 2000$ or less. Table 1 details the profile of respondents.
Table I. Sample Characteristics.

\begin{tabular}{|c|c|}
\hline Characteristic & $\%$ \\
\hline \multicolumn{2}{|l|}{ Sex } \\
\hline Male & 42.9 \\
\hline Female & 57.1 \\
\hline \multicolumn{2}{|l|}{ Age } \\
\hline $18-24$ & 16.3 \\
\hline $25-34$ & 26.7 \\
\hline $35-44$ & 22.4 \\
\hline $45-54$ & 18.8 \\
\hline 55 or older & 15.8 \\
\hline \multicolumn{2}{|l|}{ Employment status } \\
\hline Self-employed & 13.1 \\
\hline Employed by third party & 48.2 \\
\hline Student & 14.8 \\
\hline Retired & 7.7 \\
\hline Not working & 9.6 \\
\hline Another situation & 6.6 \\
\hline \multicolumn{2}{|l|}{ Education } \\
\hline Basic (9 years of schooling) & 11.4 \\
\hline Secondary ( 12 years of schooling) & 31.8 \\
\hline University & 56.8 \\
\hline \multicolumn{2}{|l|}{ Household type } \\
\hline Live alone & 14.8 \\
\hline Family with children & 26.9 \\
\hline Family without children & 51.1 \\
\hline Other & 7.2 \\
\hline \multicolumn{2}{|l|}{ Household's monthly net income } \\
\hline Less than $€ 475$ & 14.5 \\
\hline$€ 475-€ 1000$ & 31.7 \\
\hline$€ 1000-€ 2000$ & 41.8 \\
\hline More than $€ 2000$ & 12.0 \\
\hline
\end{tabular}

\section{Measures of Constructs}

The questionnaire included sections on (a) sociodemographics; (b) PEB, EA, and PBC; and (c) willingness to pay for environmental quality.

The four items measuring the construct willingness to pay for environmental quality were those used in the 2010 International Social Survey Program questionnaire (International Social Survey Program, 2010): "I would be willing to pay much higher taxes in order to protect the environment," "I would be willing to accept cuts in my standard of living to protect the environment," "I would be willing to pay much higher prices for products in general in order to protect the environment," and "I would agree to pay 10 percent more for food products that are produced and packaged in ways that are less harmful to the environment." Respondents rated each item using a 10-point Likert-type scale $(1=$ totally disagree to $10=$ totally agree $)$.

PEB was measured using a 10-statement scale including 3 -R activities (reduce-recycle-reuse) and green buying decisions. The 10 statements were adapted from the study carried 
out by Cleveland et al. (2005), Trivedi et al. (2015) and Dursun et al. (2016): "I switch off the lights in the rooms that are not being used," "I close the water tap while I do my dish washing," "I close the water tap while brushing my teeth," "I sort soda cans for recycling," "I sort papers and cardboard for recycling," "I sort glass containers for recycling," "I reuse the backside of printed sheets as draft paper," "I buy fruit and vegetables grown without pesticides or chemicals," "I buy paper products that are made from recycled materials" and "I buy household detergents and cleaning solutions that are environmentally friendly." Respondents rated each item using a 10-point Likert-type scale $(1=$ never do it to $10=$ always do it).

EA was measured by four items adapted from the studies by Stern et al. (1999) and Dono et al. (2010): "Are you a member of any group whose main aim is to preserve or protect the environment?," "In the last 12 months did you sign a petition in support of protecting the environment?," "In the last 12 months did you give money to an environmental group?," and "Have you ever voted for a candidate in an election at least in part because he or she was in favor of strong environmental protection?." These items were answered with yes/no responses. The percentage of positive (yes) answers was calculated to measure the civic participation of respondents.

Finally, PBC was assessed by three direct measures (Ajzen, 2002) that capture the perceived inhibiting effects of accessible control factors: "Keeping separate piles of rubbish for recycling is too much trouble," "I hate washing out bottles for recycling," "Recycling is too much trouble." Respondents rated each item using a 10-point Likert-type scale $(1=$ totally disagree to $10=$ totally agree). As such, the higher the response score for each item, the greater the individual's perceived difficulty in performing the behavior. The SEM hypotheses are stated as positive effects of $\mathrm{PBC}$ on other constructs; therefore, the PBC items were reversed for the purpose of SEM estimation.

The questionnaire was pre-tested by means of cognitive face-to-face interviews with a sample of 15 respondents with diverse ages and educational levels. The few changes derived from the pre-test were incorporated into the final version of the questionnaire to improve wording and minimize ambiguity. The items from the literature were subject to a translation and back-translation process to ensure accuracy. The survey questionnaire was administered by Computer-Assisted Personal Interview (CAPI) at the respondents' home.

\section{Statistical Data Analysis}

Structural equation modeling (SEM) was used to estimate the model parameters and test the associated hypotheses using the maximum likelihood method. The conceptual model was tested in a two-stage approach (Anderson \& Gerbing, 1988): first, a confirmatory factor analysis was conducted to properly evaluate the overall measurement model in terms of item and construct reliability, and convergent and discriminant validity; in a second stage, the structural relationships were tested by SEM. Model fit was evaluated using the following indexes: the goodness-of-fit index (GFI), the comparative fix index (CFI) and the incremental fit index (IFI); these reveal a good fit if greater than 0.9. The root mean square error of approximation (RMSEA) is a complement to the other measures - the acceptable maximum for RMSEA is 0.08 (Bentler, 2007; Kline, 2010). Prior to SEM estimation, an exploratory factor analysis of the PEB items was conducted to find their underlying structure.

The model was estimated to test the invariance of two segments - people with university education and people without university education - by using multigroup SEM analysis. In this analysis, the conceptual model is compared with the data structure in two groups. Nested models are organized in a hierarchical ordering with a decreasing number of parameters as parameter constraints are added one at a time (Vandenberg $\&$ Lance, 2000). The restrictive models are tested in terms of their model-data fit (Steenkamp \& Baumgartner, 1998).

Six models were tested: M0, the Unconstrained model, aims to assess whether the model structure is invariant across groups, that is, whether the individuals of the two groups conceptualize the constructs in the same way. This is tested by running the model in each group and it is considered a comparison standard to the following tests; M1, the Measurement Weights model, tests whether the two groups answer the construct items in the same way, resulting in correlation equality among the construct items. Observed item differences across groups will indicate group differences in the underlying latent construct. This model is tested by constraining the factor loadings (measurement weights) so that they are equal across groups; M2, the Structural Weights model, assesses the equality of structural path coefficients (or weights) across groups. The model is tested by constraining the structural path coefficients and the factor loadings so that they are the same across groups; M3, goes a little further than M2, by adding the constraint of equality of factor covariances; M4, the Structural Residuals model, tests the equality of loadings and structural path coefficients, covariances, and residuals; and M5, the Measurement residuals model, aims to assess whether all parameters are equal across groups by adding the equality of the measurement error variances to the constraints already tested in the other models. The chi-square difference test statistic was used to compare the model fit of nested models; when the chi-square difference of two models is significant, the model with more free estimated parameters fits the data better than the other model.

\section{Results}

\section{Item Descriptives and Factor Analysis}

Table 2 presents the mean and standard deviation for each item by group of educational level, together with the outcomes of the independent sample $t$ test for equality of means. 
Table 2. Descriptive Statistics and Standardized Item Loadings Per Educational Level.

\begin{tabular}{|c|c|c|c|c|c|}
\hline \multirow[b]{2}{*}{ Items } & \multicolumn{2}{|c|}{ Without university education } & \multicolumn{2}{|c|}{ With university education } & \multirow{2}{*}{$\frac{t \text { test }}{\text { Statistic }}$} \\
\hline & Loading & $M(S D)$ & Loading & $M(S D)$ & \\
\hline \multicolumn{6}{|l|}{ Pro-environmental behavior } \\
\hline \multicolumn{6}{|l|}{ Waste management $(\mathrm{AVE}=0.5 \mathrm{I} 3 ; \mathrm{CR}=0.759)$} \\
\hline $\begin{array}{l}\text { I sort papers and cardboard for } \\
\text { recycling }\end{array}$ & 0.868 & $7.12(2.98)$ & 0.861 & $7.98(2.66)$ & $-3.60 * *$ \\
\hline I sort glass containers for recycling & 0.873 & $7.39(3.18)$ & 0.801 & $8.31(2.59)$ & $-3.74 * *$ \\
\hline I sort aluminum cans for recycling & 0.826 & $6.53(3.36)$ & 0.806 & $7.50(3.02)$ & $-3.62 * *$ \\
\hline \multicolumn{6}{|c|}{ Energy and water saving $(\mathrm{AVE}=0.445 ; \mathrm{CR}=0.702)$} \\
\hline $\begin{array}{l}\text { I switch off the lights in the rooms that } \\
\text { are not being used }\end{array}$ & 0.495 & $8.73(1.93)$ & 0.671 & $8.59(1.95)$ & +0.88 \\
\hline $\begin{array}{l}\text { I close the water tap while I do my dish } \\
\text { washing }\end{array}$ & 0.856 & $7.80(2.64)$ & 0.790 & $8.05(2.24)$ & -1.19 \\
\hline $\begin{array}{l}\text { I close the water tap while brushing my } \\
\text { teeth }\end{array}$ & 0.822 & $8.19(2.50)$ & 0.794 & $8.18(2.37)$ & +0.02 \\
\hline \multicolumn{6}{|c|}{ Green buying and reuse (AVE $=0.491 ; C R=0.755)$} \\
\hline $\begin{array}{l}\text { I try to buy paper products made of } \\
\text { recycled paper }\end{array}$ & 0.635 & $5.94(3.02)$ & 0.618 & $6.07(2.61)$ & -0.55 \\
\hline $\begin{array}{l}\text { I reuse the backside of printed sheets as } \\
\text { draft paper }\end{array}$ & 0.465 & $8.02(2.56)$ & 0.650 & $8.31(2.12)$ & -1.48 \\
\hline $\begin{array}{l}\text { I buy fruit and vegetables grown without } \\
\text { pesticides or chemicals }\end{array}$ & 0.556 & $5.40(2.92)$ & 0.549 & $5.22(2.63)$ & +0.79 \\
\hline $\begin{array}{l}\text { I buy household detergents and cleaning } \\
\text { solutions that are environmentally } \\
\text { friendly }\end{array}$ & 0.749 & $5.68(2.68)$ & 0.573 & $5.85(2.33)$ & -0.80 \\
\hline Environmental activism ${ }^{\mathrm{a}}$ & 0.707 & $0.13(0.19)$ & 0.707 & $0.19(0.24)$ & $-3.50 * *$ \\
\hline \multicolumn{6}{|c|}{ Perceived behavior control ${ }^{\mathrm{b}}(\mathrm{AVE}=0.573 ; \mathrm{CR}=0.727)$} \\
\hline Recycling is too much trouble $(\mathrm{R})$ & 0.839 & $4.23(3.02)$ & 0.882 & $3.63(2.65)$ & $+2.51 *$ \\
\hline $\begin{array}{l}\text { Keeping separate piles of rubbish for } \\
\text { recycling is too much trouble }(R)\end{array}$ & 0.997 & $4.57(3.11)$ & 0.996 & $3.64(2.65)$ & $+3.79 * *$ \\
\hline $\begin{array}{l}\text { I hate washing out bottles for recycling } \\
(R)^{c}\end{array}$ & - & $5.17(3.39)$ & - & $4.47(3.02)$ & $+2.58^{*}$ \\
\hline \multicolumn{6}{|l|}{ Willingness to pay (AVE $=0.512 ; C R=0.807)$} \\
\hline $\begin{array}{l}\text { I would be willing to pay much higher } \\
\text { taxes in order to protect the } \\
\text { environment }\end{array}$ & 0.882 & $4.09(2.94)$ & 0.808 & $4.71(2.85)$ & $-2.59 *$ \\
\hline $\begin{array}{l}\text { I would be willing to accept cuts in } \\
\text { my standard of living to protect the } \\
\text { environment }\end{array}$ & 0.772 & $5.08(2.97)$ & 0.692 & $5.90(2.68)$ & $-3.52 * *$ \\
\hline $\begin{array}{l}\text { I would be willing to pay much higher } \\
\text { prices for products in general in order } \\
\text { to protect the environment }\end{array}$ & 0.860 & $4.44(2.94)$ & 0.907 & $5.07(2.72)$ & $-2.65^{* *}$ \\
\hline $\begin{array}{l}\text { I would agree to paying } 10 \% \text { more for } \\
\text { food products that are produced and } \\
\text { packaged in ways that are less harmful } \\
\text { to the environment }\end{array}$ & 0.828 & $4.81(3.15)$ & 0.858 & $5.31(2.85)$ & $-2.00 *$ \\
\hline
\end{tabular}

Note. $\mathrm{AVE}=$ average variance extracted; $\mathrm{CR}=$ composite reliability.

${ }^{a}$ Environmental activism is measured by a single indicator. ${ }^{b}$ Although the items of perceived behavior control were reversed because of SEM analysis, the mean values presented in this table correspond to the mean values of the original items. 'Item dropped during the purification procedure. $*_{p}<.05$. **p $<.0$ I

People with university education have the best waste recycling behavior, as suggested by the significant differences between the two groups for all items measuring waste management. In addition, they are not so worried about the effort involved in recycling as those without university education. Those with university education are more willing to pay for environmental quality and a higher percentage of EA is also found in this group. 
Table 3. Goodness-of-Fit Measures for Each Estimated Model.

\begin{tabular}{|c|c|c|c|c|c|c|c|}
\hline Model & Number of parameters & $\chi^{2}$ & $d f$ & GFI & $\mathrm{CFI}$ & IFI & RMSEA \\
\hline MO_-Unconstrained & 92 & 636.549 & 214 & 0.894 & 0.906 & 0.907 & 0.059 \\
\hline MI-Measurement weights & 81 & 665.712 & 225 & 0.889 & 0.902 & 0.903 & 0.058 \\
\hline M2-Structural weights & 70 & 671.654 & 236 & 0.888 & 0.903 & 0.904 & 0.057 \\
\hline M3-Structural covariances & 68 & 679.740 & 238 & 0.886 & 0.902 & 0.902 & 0.057 \\
\hline M4-Structural residuals & 61 & 695.215 & 245 & 0.883 & 0.900 & 0.900 & 0.057 \\
\hline M5-Measurement residuals & 46 & 771.812 & 260 & 0.870 & 0.886 & 0.886 & 0.059 \\
\hline
\end{tabular}

Note. GFI = goodness-of-fit index; CFI = comparative fix index; IFI = incremental fit index; RMSEA = root mean square error of approximation.

The exploratory factor analysis conducted on the items measuring PEB revealed three factors, termed Waste Management, Energy \& Water Saving, and Green Buying \& Reuse. Table 2 presents the items making up each of the PEB factors. These factors were then estimated by confirmatory factor analysis (CFA) as individual correlated factors in the overall measurement model, and subsequently in the SEM model. An overall measurement model with all latent variables and their corresponding items was tested. One item was dropped due to low standardized loadings (less than $0.5)$. After this purification procedure, items were deemed reliable. Table 2 presents for each construct the average variance extracted (AVE) and the composite reliability (CR) measures. All constructs have CR above 0.7 which is evidence of good construct reliability. Moreover, except for Energy \& Water Saving and Green Buying \& Reuse, all constructs have AVE values above the minimum required value of 0.50 (Bagozzi \& Yi, 1988). However, as Fornell and Larcker (1981) argue, this does not compromise constructs' convergent validity because they are strongly reliable (the respective CR is above 0.7 as above mentioned). The Fornell and Larcker's (1981) criterion (i.e., the square root of the AVE values for each latent construct should be higher than the correlations between the construct and all other constructs) is also valid for all constructs, supporting the evidence of discriminant validity.

\section{Multigroup Analysis Results}

Table 3 shows the chi-square statistic for each fitted model. The data seem to depart from the unconstrained model (M0) without major differences between models. The goodness-offit indexes fall within the recommended boundaries in all the estimated models and suggest the good fit of the models.

Table 4 presents the outcomes of the nested model comparison. Pairwise comparisons between models M1 to M5 lead to the choice of M2, meaning that the loadings and the structural path coefficients are invariant in the two groups. However, differences between the unconstrained model (M0), where all the two group parameters are free, and the other models, show that all the models have a worse fit than M0. Therefore, M0, the model which presented the best fit was chosen; this means that there could be differences for
Table 4. Nested Model Comparisons.

\begin{tabular}{lrrr}
\hline Model & $\Delta d f$ & $\Delta \chi 2$ & $p$ value \\
\hline MI vs. M0 & \multicolumn{1}{c}{ II } & 29.163 & .002 \\
M2 vs. M0 & 22 & 35.105 & .038 \\
M3 vs. M0 & 24 & 43.191 & .009 \\
M4 vs. M0 & 31 & 58.666 & .002 \\
M5 vs. M0 & 46 & 135.263 & .000 \\
M2 vs. MI & 11 & 5.942 & .877 \\
M3 vs. MI & 13 & 14.028 & .372 \\
M4 vs. MI & 20 & 29.502 & .078 \\
M5 vs. MI & 35 & 106.100 & .000 \\
M3 vs. M2 & 2 & 8.086 & .018 \\
M4 vs. M2 & 9 & 23.560 & .005 \\
M5 vs. M2 & 24 & 100.158 & .000 \\
M4 vs. M3 & 7 & 15.475 & .030 \\
M5 vs. M3 & 22 & 92.072 & .000 \\
M5 vs. M4 & 15 & 76.597 & .000 \\
\hline
\end{tabular}

both educational groups in any model parameter. This result confirms the moderator role of educational level. Figure 2 shows only the structural model results, namely the standardized regression coefficient estimates and the squared multiple correlation of each dependent construct, for those with university education and for those without university education. Dashed arrows mean nonsignificant relationships.

Regarding the structural path coefficients estimated for people without university education (Figure 2A), the findings show that none of the PEB factors affects willingness to pay for environmental quality; therefore, H1 (PEB is positively related to WTP) is not confirmed. EA influences willingness to pay for environmental quality $(\hat{\beta}=+0.232$, $p<.1$ ) and, thus, H5 (EA is positively related to WTP) is supported. Its impact on PEB is only significant in the case of waste management $(\hat{\beta}=+0.386, p<.05)$ and green buying and reuse $(\hat{\beta}=+0.498, p<.05)$; therefore, we consider that $\mathrm{H} 4$ (EA is positively related to $\mathrm{PEB}$ ) is partially supported in this segment. $\mathrm{PBC}$ has a positive effect on PEB factors - waste management $(\hat{\beta}=+0.256, p<$ $.05)$, energy and water saving $(\hat{\beta}=+0.285, p<.05)$, and green buying and reuse $(\hat{\beta}=+0.229, p<.05)$; therefore, $\mathrm{H} 2$ (PBC is positively related to PEB) is supported. Moreover, $\mathrm{PBC}$ has a positive effect on willingness to pay 


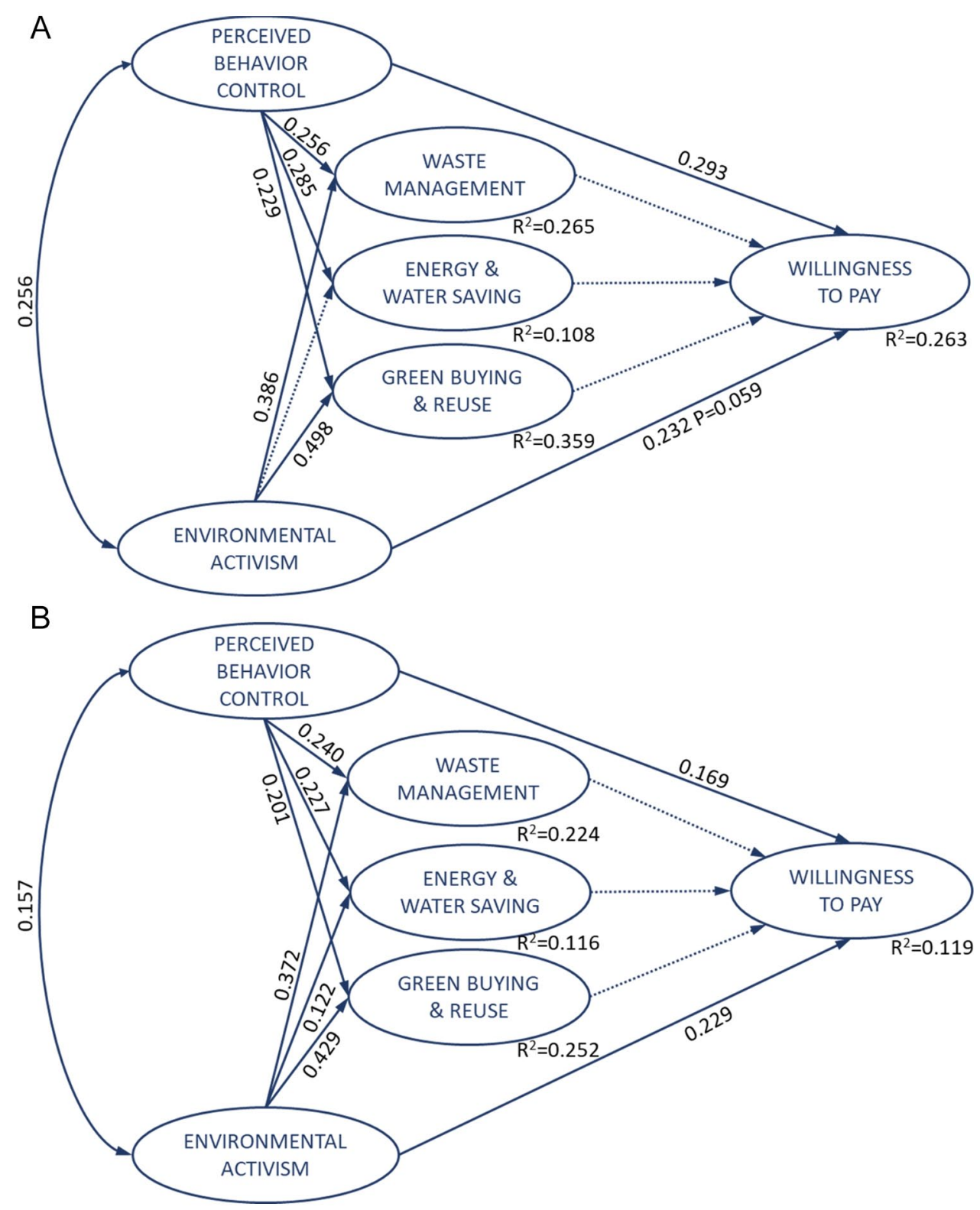

Figure 2. (A): Standardized regression coefficient estimates for the structural Model M0 for the subgroup without university education; (B) standardized regression coefficient estimates for the structural Model MO for the subgroup with university education.

for environmental quality $(\hat{\beta}=+0.293, p<.05)$; thus, $\mathrm{H} 3$ ( $\mathrm{PBC}$ is positively related to willingness to pay for environmental quality) is supported.

Regarding the structural path coefficients estimated for people with university education (Figure 2B), the findings show that none of the PEB factors affects willingness to pay for environmental quality; therefore, $\mathrm{H} 1$ is not confirmed in this segment. PBC has a positive effect on PEB factors - waste management $(\hat{\beta}=+0.240, p<.05)$, energy and water saving $(\hat{\beta}=+0.227, p<.05)$, and green buying and reuse $(\hat{\beta}=0.201, p<.05)$; therefore, $\mathrm{H} 2$ is supported in this segment. Moreover, $\mathrm{PBC}$ has a positive effect on willingness to pay for environmental quality $(\hat{\beta}=+0.169, p<.05)$, thus supporting H3. EA influences willingness to pay for environmental quality $(\hat{\beta}=+0.229$, $p<.05$ ), and thus H5 is supported. EA's impact on PEB is significant for all factors - waste management $(\hat{\beta}=+0.372$, $p<.05)$, energy and water saving $(\hat{\beta}=+0.122, p<.05)$, and green buying and reuse $(\hat{\beta}=+0.429, p<.05)$, which supports $\mathrm{H} 4$. 
Finally, H6 (the relationships among the model constructs are stronger for people with university education than for those without university education) is not supported. As the estimated regression coefficients reveal, the relationships identified as significant are stronger in the without university education subgroup than in the university education subgroup.

\section{Discussion and Conclusion}

The concern for environmental quality and protection has entered the agendas of governments, companies, and citizens. Although at different rhythms, most countries and societies are adopting measures aimed at encouraging behavioral change and adherence to environmentally friendly practices and policies (EEA, 2020). On the part of citizens, deciding to pay higher prices for environmentally friendly products and agreeing to pay fees / taxes that will revert to actions aimed at promoting environmental quality are moderate forms of environmental actions that can still bear fruit (Marbuah, 2016). Most studies on the influencing factors of citizens' willingness to pay higher prices and/or higher taxes for environmental quality are conducted from a regression modeling approach. Considering the complexity of citizens' psychology, this study combines a SEM approach to build a model aimed at exploring how PBC, EA, and PEB determine Willingness to Pay (WTP) more for environmental quality; additionally, we evaluate how educational level affects the relationships between these constructs.

The outcomes reveal that WTP more for environmental quality is significantly influenced by $\mathrm{PBC}$ and EA, which validates the use of these constructs to influence citizens' adherence to environmental protection policies. Moreover, the outcomes show that educational level influences WTP more for environmental quality, although in the opposite direction of previous research. People with more education tend not only to be more concerned about the environment but also to engage in actions that promote and support political decisions for its protection (Davis et al., 2011; Gelissen, 2007; Ivanova \& Tranter, 2008) while the effects revealed by our model are stronger in the subgroup without university education than in the university education subgroup. This suggests people's understanding of what can be done to favor environmental quality differs according to their educational level and, on the other hand, that any strategy aimed to stimulate the intention to pay more for environmental quality (either by raising taxes or increasing prices of goods and services or cutting living standards) is likely to be more successful among those without university education than among those with university education. Respondents with university education are already more aware of the environmental issue and more involved in concrete environmental protection actions than those with less education (the former have stronger EA, more frequently adopt pro-environmental actions, namely in waste management activities, and have a higher PBC; see Table 2), which explains their weaker response to future policies to improve environmental quality: They are already doing something for the environment, so the qualitative leap they can take is smaller than among those who are doing less.

Despite the positive impact of PBC and EA on PEB, the effect of PEB factors (waste management, energy and water saving, and green buying and reuse) on WTP more for environmental quality is not significant. In short, having ecofriendly behaviors, such as separating waste and recycling, saving water and energy, and buying "green" goods, does not influence the willingness to support an "additional" cost in support of the environment, but our results suggest that stronger PBC and stronger EA contribute positively to accepting higher prices and/or higher taxes if that benefits the environment. Therefore, the two dimensions that need to be addressed to obtain citizens' acceptance of public policies involving higher taxes or convincing consumers to choose eco-friendly products even if they cost more, are EA and PBC.

Although Portuguese citizens are increasingly concerned about the environment, they do not reveal many changes in terms of behavior. According to the third Study of the Observatory of Conscious Consumption, nearly $70 \%$ of Portuguese consider themselves as "environmentally concerned" but only a minority (about 30\%) adopt eco-friendly behaviors such as using public transport in daily commuting (instead of the car), or buying organic products; additionally, the majority are unwilling to pay environmental fees and have little commitment to EA (Observatório do Consumo Consciente [OCC], 2018). However, there are signs of receptiveness to change. According to a recent study by the consultancy agency Accenture (2019), 83\% of Portuguese believe it is important that companies create environmentally friendly products, $81 \%$ plan to buy more environmentally friendly products in the next 5 years, and $50 \%$ are willing to pay for products that can be reused or recycled. Moreover, Green Taxation is a governmental program, revised in 2015, aimed at stimulating innovation and sustainable development to help reconcile environmental protection and economic growth. In practice, Green Taxation is reflected at the level of the various taxes that already exist in Portugal. On one hand, the most sustainable behaviors provide tax benefits and, on the other, behaviors harmful to the environment are penalized. Citizens have tax benefits, for example, in the purchase of electric vehicles or in households' adoption of renewable energy sources, and have penalties for non-ecofriendly behaviors, such as the use of non-reusable plastic bags (Rankia, 2019). EA, which proved to be an important factor to incentivize citizens to bear costs in favor of the environment, is strengthened with this program: tax benefits encourage EA, which, although moderate, ultimately contributes to citizens' awareness of the need to change their behaviors and consumption patterns to others that are more sustainable. EA can also be performed in the private sphere 
where citizens can contribute to environmental quality by adopting eco-friendly consumption patterns. The intention expressed by many Portuguese to buy environmentally friendly products in the short run (Accenture, 2019) underlines the need for companies to increase their commitment to more sustainable business practices, namely increasing the offer of green products. The green product market is still in its infancy in Portugal but shows signs of growth due to the growing number of consumers willing to use them (Marktest, 2013; Sottomayor, 2004). In addition, it is important that companies communicate what they are doing to foster sustainability and what positive impact they will provide with their products and services. Other factors connected to EA, such as signing a petition in support of environmental protection or donating money to an environmental group, are still limited in Portuguese society; it would therefore be beneficial to have more participatory environmental education campaigns so that citizens are stimulated to take a more proactive attitude to defending the environment. This is particularly important among Portuguese aged between 15 and 24 years as they show little interest in environmental problems (OCC, 2018), despite the awareness campaigns that have already taken place.

PBC has a positive effect on WTP, which implies finding ways of changing people's attitudes so that they recognize environmental quality is dependent upon everyone making their personal contribution. The stronger the $\mathrm{PBC}$, the more likely a person is to exhibit PEB and a willingness to pay for environmental quality. Our data show that those without university education have stronger inhibiting factors than those with university education, indicating that this group may benefit from informative campaigns targeted to convey the message that eco-friendly behaviors are not difficult to implement, environmental protection is everyone's responsibility, and environmental protection starts with a change in each person's behaviors. Campaigns to inform people of the advances being made can also increase citizens' commitment to the environment. Behavioral sciences generally acknowledge that peoples' commitment and performance is increased by feedback and knowledge of results (Ashford \& Cummings, 1985; Fishbach et al., 2010); hence, spreading information about the outcomes of specific policies is likely to encourage citizens to pursue more environmentally friendly behavior and support future policies for environment quality.

In addition to the evident importance to marketing and public policy practices, these findings also advance the body of knowledge on this matter. Previous research (e.g., Han et al., 2011; Kauder et al., 2018; Marbuah, 2016; Witzke \& Urfei, 2001) relies largely on regression models, either logistic, ordered probit, or ordinary least squares depending on how the dependent variable is measured. However, these methodological approaches are simplistic since they do not recognize the interrelationship of the various factors influencing the willingness to pay for environment quality. The
SEM proved to be an adequate methodological approach to investigate WTP more for environmental quality given that significant relationships were found among predictors. Moreover, citizens are not homogeneous in their response to WTP measures: Educational level helps reveal distinct segments. A better understanding of the determinants of WTP for environmental quality is thus gleaned when sociodemographic characteristics are considered.

Although much has been done to improve environmental quality, the effort to pursue strategies with positive results on citizens' adoption of environmentally friendly behaviors and to support environmental protection policies must be underpinned by empirical knowledge grounded on intensive and extensive research. Intentions are often regarded as the main determinant of actual behavior (Fishbein \& Ajzen, 2010) and all studies that seek to understand what affects the desire or willingness to behave in a specific way are important to the definition of strategies on how to stimulate actual behavior. We studied willingness to pay for the environmental quality, more specifically the intention or state of being prepared to do something rather than an actual behavior. Future studies should also measure actual behavior, namely longitudinal studies in which the measurement of intentions precedes the measurement of actual behavior to determine whether behavior converges with intentions. In the context of WTP for environmental quality, future research might investigate additional variables related to government and institutional trust, since most public policies aimed at fostering environment protection are implemented by state institutions.

The following limitations of the current study should be noted. First, the generalization of the results to Portugal is limited as the study did not cover the entire country. Second, although the results demonstrated the suitability of a SEM approach, more research is required to be confident about the most appropriate model in the context of WTP for environmental quality studies, that is, replicating the model in other countries or regions. Third, the sample was slightly biased toward university education, that is, the sample contains a higher percentage of respondents with university education than the overall Portuguese population. While this was inevitable due to the length of the survey questionnaire (it took approximately $40 \mathrm{~min}$ to complete) and powers of reasoning required, we acknowledge that this may weaken the representativeness of the sample. Notwithstanding, the article's contribution remains relevant as the focus of the analysis was mostly comparative and relational.

\section{Acknowledgments}

The authors thank Prof. Paula Castro for her comments and suggestions on the earlier versions of this article.

\section{Declaration of Conflicting Interests}

The author(s) declared no potential conflicts of interest with respect to the research, authorship, and/or publication of this article. 


\section{Funding}

The author(s) disclosed receipt of the following financial support for the research and/or authorship of this article: This work was supported by Fundação para a Ciência e Tecnologia, grant UIDB/00315/2020.

\section{Human and Animal Welfare Statements}

Our data were collected by means of a survey following the guidelines of ICC/ESOMAR Code.

\section{ORCID iD}

Paula Vicente (iD https://orcid.org/0000-0003-4387-6400

\section{References}

Accenture. (2019). Consumers willing to pay more for 'environmentally friendly' products. https://newsroom.accenture.pt/pt/ news/consumers-environment-product.htm

Afroz, R., Masud, M., Akhtar, R., Islam, M., \& Duasa, J. (2015). Consumer purchase intention towards environmentally friendly vehicles: An empirical investigation in Kuala Lumpur. Environmental Science and Pollution Research, 22, 16153-16163.

Ajzen, I. (1985). From intentions to actions: A theory of planned behavior. In J. Kuhl \& J. Beckman (Eds.), Action-control: From cognition to behavior (pp. 11-39). Springer.

Ajzen, I. (1991). The theory of planned behavior. Organizational Behavior and Human Decision Processes, 50(2), 179-211.

Ajzen, I. (2002). Perceived behavior control, self-efficacy, locus of control, and the theory of planned behavior. Journal of Applied Social Psychology, 32(4), 665-683.

Ajzen, I. (2020). The theory of planned behavior: Frequently asked questions. Human Behavior and Emerging Technologies, 2, 314-324.

Al Mamun, A., Fazal, S., Ahmad, G., Yaacob, M., \& Mohamad, M. (2018). Willingness to pay for environmentally friendly products among low-income households along coastal peninsular Malaysia. Sustainability, 10, 1316.

Anderson, J., \& Gerbing, D. (1988). Structural equation modeling in practice: A review and recommended two-step approach. Psychological Bulletin, 103(3), 411-423.

Agência Portuguesa do Ambiente. (2014). Urban waste 2014. https://apambiente.pt/index.php?ref=16\&subref=84\&sub2ref= $108 \&$ sub3ref $=209$

Armitage, C., \& Conner, M. (2001). Efficacy of the theory of planned behaviour: A meta-analytic review. British Journal of Social Psychology, 40(4), 471-499.

Ashford, S., \& Cummings, L. (1985). Proactive feedback seeking: The instrumental use of the information environment. Journal of Occupational Psychology, 58, 67-79.

Bagozzi, R., \& Yi, Y. (1988). On the evaluation of structural equation models. Journal of the Academy of Marketing Sciences, 16, 74-94.

Bentler, P. (2007). On tests and indices for evaluating structural models. Personality and Individual Differences, 42, 825-829.

Biswas, A. (2016). A study of consumers' willingness to pay for green products. Journal of Advanced Management Science, 4(3), 211-215.
Castro, P., Uzelgun, M., \& Bertoldo, R. (2017). Climate change activism between weak and strong environmentalism: Advocating social change with moderate argumentation strategies? In C. Howarth \& E. Andreouli (Ed.), The social psychology of everyday politics (pp. 1-22). Routledge.

Chen, M. (2017). Modeling an extended theory of planned behavior model to predict intention to take precautions to avoid consuming food with additives. Food Quality and Preference, 58, 24-33.

Cleveland, M., Kalamas, M., \& Laroche, M. (2005). Shades of green: Linking environmental locus of control and pro-environmental behaviors. Journal of Consumer Marketing, 22(4), 198-212.

Cone Communications. (2015). Attitudes, perceptions and behaviors around corporate social responsibility. http://www. conecomm.com/research-blog/2015-cone-communicationsebiquity-global-csr-study

Davis, J., Le, B., \& Coy, A. (2011). Building a model of commitment to the natural environmental to predict ecological behavior and willingness to sacrifice. Journal of Environmental Psychology, 31(3), 257-265.

De Groot, J., \& Steg, L. (2009). Morality and prosocial behavior: The role of awareness, responsibility and norms in the norm activation model. The Journal of Social Psychology, 149(4), 425-449.

Dono, J., Webb, J., \& Richardson, B. (2010). The relationship between environmental activism, pro-environmental behaviour and social identity. Journal of Environmental Psychology, 30(2), 178-186.

Dursun, I., Kabadayi, E., Koksal, C., \& Tuger, A. (2016). Proenvironmental consumption: Is it really all about the environment? Journal of Management, Marketing and Logistics, 3(2), 2148-6670.

European Environment Agency. (2020). The European environment-State and outlook 2020. https://www.eea.europa.eu/ soer $/ 2020$

Fishbach, A., Eyal, T., \& Finkelstein, S. (2010). How positive and negative feedback motivate goal pursuit. Social \& Personality Psychology Compass, 4(8), 517-530.

Fishbein, M., \& Ajzen, I. (2010). Predicting and changing behavior: The reasoned action approach. Taylor \& Francis.

Fornell, C., \& Larcker, D. F. (1981). Evaluating structural equation models with unobservable variables and measurement error. Journal of Marketing Research, 18(1), 39-50.

Franzen, A., \& Meyer, R. (2009). Environmental attitudes in crossnational perspective: A multilevel analysis of the ISSP 1993 and 2000. European Sociological Review, 26(2), 219-234.

Gao, L., Wang, S., Li, J., \& Li, H. (2017). Application of the extended theory of planned behavior to understand individual's energy saving behavior in workplaces. Resources, Conservation \& Recycling, 127, 107-113.

Gelissen, J. (2007). Explaining popular support for environmental protection: A multilevel analysis of 50 nations. Environment and Behavior, 39(3), 392-415.

Haller, M., \& Hadler, M. (2008). Dispositions to act in favor of the environment: Fatalism and readiness to make sacrifices in crossnational perspective. Sociological Forum, 23(2), 281-311.

Han, H. (2014). The norm activation model and theory-broadening: Individuals' decision-making on environmentally responsible 
convention attendance. Journal of Environmental Psychology, 40, 462-471.

Han, H., Hsu, L.-T., Lee, J.-S., \& Sheu, C. (2011). Are lodging customers ready to go green? An examination of attitudes, demographics, and eco-friendly intentions. International Journal of Hospitality Management, 30(2), 345-355.

Hohnen, P. (2007). Corporate social responsibility: An implementation guide for business. International Institute for Sustainable Development. http://www.iisd.org/pdf/2007/csr_guide.pdf

International Social Survey Programme. (2010). ZA5500: International Social Survey Programme: Environment III [GESIS Data Archive]. https://dbk.gesis.org/dbksearch/sdesc2.asp?no $=5500 \& \mathrm{db}=\mathrm{e} \& \mathrm{doi}=10.4232 / 1.11366$

Ivanova, G., \& Tranter, B. (2004). Willingness to pay for "the environment" in cross-national perspective [Paper presentation]. The Australasian Political Studies Association Conference. https://www.adelaide.edu.au/apsa/docs_papers/Others/ IvanovaandTranterAPSA.pdf0212

Ivanova, G., \& Tranter, B. (2008). Paying for environmental protection in cross national perspective. Australian Journal of Political Science, 43(2), 169-188.

Jin, M., \& Shriar, A. (2013). Exploring the relationship between social capital and individuals' policy preferences for environmental protection: A multinomial logistic regression analysis. Journal of Environmental Policy \& Planning, 15(3), 427-446.

Jones, N., Evangelinos, K., Halvadakis, C., Isofides, T., \& Sophoulis, C. (2010). Social factors influencing perceptions and willingness to pay for a market-based policy aiming on solid waste management. Resources, Conservation \& Recycling, 54, 533-540.

Kashima, Y., Paladino, A., \& Margetts, E. (2014). Environmentalist identity and environmental striving. Journal of Environmental Psychology, 38, 64-75.

Kauder, B., Potrafke, N., \& Ursprung, H. (2018). Behavioral determinants of proclaimed support for environment protection policies. European Journal of Political Economy, 54, 26-41.

Kline, R. (2010). Principles and practice of structural equation modeling. The Guilford Press.

Krajhanzl, J. (2010). Environmental and pro-environmental behavior. In E. Řehulka (Eds.), School and health 21, health education: International experiences (pp. 251-274). Masaryk University Press.

Kyselá, E. (2015). Acceptability of environmental policies in the Czech Republic: A comparison with willingness to make economic sacrifices. Socialni Studia, 12(3), 179-198.

Lavik, R. (2002, August 28-31). Pro-environmental attitudesDo they matter? [Paper presentation]. The Esa-workshopSociology of Consumption, Bergen, Norway. https://www. noexperiencenecessarybook.com/adeeA/pro-environmentalattitudes-do-they-matter-sifo.html

Liobikien, G., \& Poškus, M. (2019). The importance of environmental knowledge for private and public sphere pro-environmental behavior: Modifying the value-belief-norm theory. Sustainability, 11, 3324.

Maichum, K., Parichatnon, S., \& Peng, K. (2016). Application of the extended theory of planned behavior model to investigate purchase intention of green products among Thai consumers. Sustainability, 8, 1077.

Mannetti, L., Pierro, A., \& Livi, S. (2004). Recycling: Planned and self-expressive behaviour. Journal of Environmental Psychology, 24(2), 227-236.
Marbuah, G. (2016). Willingness to pay for environmental quality and social capital influence in Sweden [FAERE Working Paper]. https://econpapers.repec.org/paper/faewpaper/2016.13.htm

Marktest. (2013). TGI measures consumption changes in Portugal. http://www.marktest.com/wap/a/n/id 1b37.aspx

Marktest. (2019). Recycling habits. https://www.novoverde.pt/PDF -docs/ReportMarktest_Barometro_Reciclagem_Mai2019_2\% C2\%AAv_SN.pdf

Nezakati, H., Hosseinpour, M., \& Hassan, M. (2014). Government Concerns of Consumers' Intention to Purchase Green Products (Preliminary Study-Malaysia Evidence). Journal of Applied Sciences, 14, 1757-1762.

Observatório do Consumo Consciente. (2018). Portuguese are more concerned about the environment, but they don't change behavior. https://www.ambientemagazine.com/portuguesesestao-mais-preocupados-com-o-ambiente-mas-nao-mudamcomportamentos/

Organisation for Economic Co-Operation and Development. (2003). Glossary of environment statistics (Studies in Methods, Series F, 67). Department for Economic and Social Information and Policy Analysis, Statistics Division.

O'Fallon, M. J., Gursoy, D., \& Swanger, N. (2007). To buy or not to buy: Impact of labeling on purchasing intentions of genetically modified foods. International Journal of Hospitality Management, 26(1), 117-130.

Orecchia, C., \& Zoppoli, P. (2007). Consumerism and environment: Does Consumption behaviour affect environmental quality? (CEIS Working Paper No. 261). https://ssrn.com/ abstract $=1719507$

Oreg, S., \& Katz-Gerro, T. (2006). Predicting pro-environmental behavior cross-nationally: Values, the theory of planned behavior, and value-belief-norm theory. Environment and Behavior, $38,462-483$.

Paço, A., \& Raposo, M. (2009). "Green” segmentation: An application to the Portuguese consumer market. Marketing Intelligence \& Planning, 27(3), 364-379.

Paço, A., \& Raposo, M. (2010). Green consumer market segmentation: Empirical findings from Portugal. International Journal of Consumer Studies, 34(4), 429-436.

Pordata. (2019). Municipal waste recycling rate. https://www. pordata.pt/Europa/Taxa + de + reciclagem + dos + res $\% \mathrm{C} 3 \% \mathrm{ADd}$ uos + municipais-3426

Punzo, G., Panarello, D., Pagliuca, M., Castellano, R., \& Aprile, M. (2019). Assessing the role of perceived values and felt responsibility on pro-environmental behaviours: A comparison across four EU countries. Environmental Science \& Policy, 101, 311-322.

Rafail, P., \& Freitas, I. (2017). Permeable participation: Civic engagement and protest mobilization in 20 OECD countries, 1981-2008. Sociological Perspectives, 60(3), 557-574.

Rajapaksa, D., Islam, M., \& Managi, S. (2018). Pro-environmental behavior: The role of public perception in infrastructure and the social factors for sustainable development. Sustainability, 10(4), Article 937.

Rankia. (2019). Green Taxation: what is green tax reform? https:// www.rankia.pt/fiscalidade/fiscalidade-verde/

Sang, P., Yao, H., Zhang, L., Wang, S., Wang, Y., \& Liu, J. (2020). Influencing factors of consumers' willingness to purchase green housing: A survey from Shandong Province, China. Environment, Development and Sustainability, 22(5), 4267-4287. 
Schoor, M. (2013). Ecologically conscious consumption in Portugal [Master's thesis]. http://bdigital.ufp.pt/handle/10284/3948

Schwartz, S. (1977). Normative influence on altruism. In L. Berkowitz (Ed.), Advances in experimental social psychology (Vol. 10, pp. 221-279). Academic Press.

Schwartz, S., \& Howard, J. (1981). A normative decision-making model of altruism. In J. P. Rushton \& R. M. Sorrentino (Eds.), Altruism and helping behavior (pp. 89-211). Lawrence Erlbaum.

Sustainable Governance Indicators. (2016). Global Environmental Protection Report. Bertlsmann Stiftung. http://www.sgi-network .org/docs/2016/thematic/SGI2016_Global_Environmental_ Protection.pdf

Shin, Y., Im, J., Jung, S., \& Severt, K. (2018). The theory of planned behavior and the norm activation model approach to consumer behavior regarding organic menus. International Journal of Hospitality Management, 69, 21-29.

Silva, A. (2015). Green products market: trends in Portugal vis-àvis Europe. http://repositorio.uac.pt/handle/10400.3/3600

Soromenho-Marques, V. (2005). International policy on environment and sustainable development. Balance and perspectives. Publicações Europa-América.

Sottomayor, M. (2004). Consumption of biological products in Portugal and "conversion" products. Universidade Católica Portuguesa, Centro de Estudos de Gestão e Economia Aplicada. http://www.isa.utl.pt/files/pub/deasr/docs/sem04/05_mar /5bWTP.pdf

Steenkamp, J., \& Baumgartner, H. (1998). Assessing measurement invariance in cross-national consumer research. Journal of Consumer Research, 25(1), 78-90.

Stern, P. (2000). Toward a coherent theory of environmentally significant behavior. Journal of Social Issues, 56, 407-424.

Stern, P., Dietz, T., Abel, T., Guagnano, G., \& Kalof, L. (1999). A value-belief-norm theory of support for social movements: The case of environmentalism. Human Ecology Review, 6(2), 81-97.

Tan, C., Ooi, H., \& Goh, Y. (2017). A moral extension of the theory of planned behavior to predict consumers' purchase intention for energy-efficient household appliances in Malaysia. Energy Policy, 107, 459-471.

Tavares, B. (2013). The environment and environmental policies in Portugal: a contribution to a historical approach [Master's thesis]. Universidade Aberta. https://repositorioaberto.uab.pt/ bitstream/10400.2/2757/1/O\%20Ambiente\%20e\%20as\%20 Pol\%C3\%ADticas\%20Ambientais\%20em\%20Portugal.pdf

Thompson, V. (2017). Role of business in environmental protection. http://smallbusiness.chron.com/role-businessenvironmental-protection-59370.html

Thornton, A. (2009). Public attitudes and behaviours towards the environment-Tracker survey: A report to the Department for Environment, food and rural affairs by TNS. https://sp .ukdataservice.ac.uk/doc/6366/mrdoc/pdf/6366userguide.pdf
Trivedi, R., Patel, J., \& Savalia, J. (2015). Pro-environmental behaviour, locus of control and willingness to pay for environmental friendly products. Marketing Intelligence \& Planning, 33(1), 67-89.

21st Session of the Conference of the Parties. (2015). Paris 2015 Getting a global agreement on climate change. http://www. green-alliance.org.uk/resources/Paris\%202015-getting\%20 a\%20global\%20agreement $\% 20$ on $\% 20$ climate $\% 20$ change.pdf

United Nations. (2008). Achieving sustainable development and promoting development cooperation. United Nations Department of Economic and Social Affairs. http://www. un.org/en/ecosoc/docs/pdfs/fina_08-45773.pdf

Valle, P., Reis, E., Menezes, J., \& Rebelo, E. (2004). Behavioral determinants of household recycling participation: The Portuguese case. Environment and Behavior, 36, 505-540.

van Birgelen, M., Semeijn, J., \& Behrens, P. (2011). Explaining pro-environment consumer behavior in air travel. Journal of Air Transport Management, 17, 125-128.

Vandenberg, R., \& Lance, C. (2000). A review and synthesis of the measurement invariance literature: Suggestions, practices, and recommendations for organizational research. Organizational Research Methods, 3, 4-70.

Verma, V., \& Chandra, B. (2018). An application of theory of planned behavior to predict young Indian consumers' green hotel visit intention. Journal of Cleaner Production, 172, 1152-1162.

Vicente, P., \& Reis, E. (2007). Segmenting households according to recycling attitudes in a Portuguese urban area. Resources, Conservation \& Recycling, 52(1), 1-12.

Vicente, P., \& Reis, E. (2008). Factors influencing households' participation in recycling. Waste Management \& Research, 26(2), 140-146.

Wang, S., Fan, J., Zhao, D., Yang, S., \& Fu, Y. (2016). Predicting consumers' intention to adopt hybrid electric vehicles: Using an extended version of the theory of planned behavior model. Transportation, 43, 123-143.

Wang, S., Wang, J., Li, J., \& Yang, F. (2020). Do motivations contribute to local residents' engagement in pro-environmental behaviors? Resident-destination relationship and pro-environmental climate perspective. Journal of Sustainable Tourism, 28(6), 834-852.

Witzke, H., \& Urfei, G. (2001). Willingness to pay for environmental protection in Germany: Coping with the regional dimension. Regional Studies, 35(3), 207-214.

Wu, S., \& Chen, J. (2014). A model of green consumption behavior constructed by the theory of planned behavior. International Journal of Marketing Studies, 6, 119-132.

Zhang, X., Geng, G., \& Ping, S. (2017). Determinants and implications of citizen's environmental complaint in China: Integrating theory of planned behavior and norm activation model. Journal of Cleaner Production, 166, 148-156. 